\title{
Presynaptic Initiation by Action Potentials of Retrograde Signals in Developing Neurons
}

\author{
Marie-Pierre Primi and Peter G. H. Clarke \\ Institut de Biologie Cellulaire et de Morphologie, Université de Lausanne, 1005 Lausanne, Switzerland
}

Until recently, the only means by which electrical activity was believed to initiate retrograde signals was via postsynaptic events: modulated synthesis or release of trophic factors. We have evidence in chick embryos for a presynaptic initiation of retrograde signals from the retina to the isthmo-optic nucleus, which is known to undergo 55\% neuron death between embryonic days 12 and 17 and to become laminated during this period. Intraocular injections of saxitoxin just before embryonic day 14 reduce neuron death and prevent lamination in the isthmo-optic nucleus within as few as $6 \mathrm{hr}$. We show that these rapid effects are attributable to the direct action of saxitoxin on the isthmo-optic terminals. Alternative possibilities, such as an indirect effect via the target cells, are ruled out by control experiments. Normally, action potentials may lead to a chain of second messenger events in the axon terminal that is signaled retrogradely via the transport of a long-lived second messenger.

Key words: chicken embryo; electrical activity; isthmo-optic nucleus; retrograde signal; neuronal death; nervous system; brain; development
Electrical activity affects profoundly the development of the nervous system. The means by which this occurs are multiple but include activity-dependent retrograde signals that affect the survival and differentiation of the parent neurons (Bear and Colman, 1990; Clarke, 1991; Wingate and Thompson, 1994). It generally is assumed that such effects must involve modulation of the production or release by the postsynaptic cells of neurotrophic factors (Zafra et al., 1991; Lindholm et al., 1994; Thoenen, 1995). We here present evidence that, quite apart from such postsynaptic events, the action potentials already initiate survival signals at the level of the presynaptic axons.

The chosen system for our experiments is the projection in chick embryos of the isthmo-optic nucleus (ION) to the contralateral retina (Fig. 1). This provides a convenient situation for studying retrograde signals, because the target of the ION-the retina-can be manipulated readily by the intraocular injection of pharmacological agents. The axons of the ION are known to terminate mainly on association amacrine cells in the retina (Uchiyama et al., 1995); the synapses begin to be detectable at $\sim$ E13 (Fritzsch et al., 1990). The main input to the ION is from the optic tectum (Crossland and Hughes, 1978) and is excitatory (Crossland, 1979). The first synapses in the ION are formed just before embryonic day (E) 14 (Angaut and Raffin, 1981). Retrograde influences from the retina on the developing ION have been studied in detail (O'Leary and Cowan, 1984; Clarke, 1992; von Bartheld et al., 1994). The ION loses $\sim 55 \%$ of its neurons between E12.5 and E16.5 and takes on a laminated appearance owing to the realignment of its neuronal perikarya from E14 onward (Cowan and Wenger, 1968; Clarke and Kraftsik, 1996),

Received Jan. 14, 1997; revised Feb. 24, 1997; accepted March 7, 1997.

This work was supported by Grants 30883.91 and 40709.94 from the Swiss National Foundation for Scientific Research. We thank G. Escher, G. M. Innocenti, and A. Posada for their comments on this manuscript; F. Tercier and N. Turrian for histology; and C. Vaclavik for typing.

Correspondence should be addressed to Dr. Peter G. H. Clarke, Institut de Biologie Cellulaire et de Morphologie, Université de Lausanne, Rue du Bugnon 9, 1005 Lausanne, Switzerland.

Copyright (C) 1997 Society for Neuroscience 0270-6474/97/174253-09\$05.00/0 which is of particular relevance to the present study because the neuronal death can be reduced and the process of lamination prevented if intraretinal action potentials are blocked (Péquignot and Clarke, 1992a,b).

The starting point of our present study is the observation that both of these effects occur unexpectedly soon after the activity blockade-too soon to be readily explicable in terms of accepted mechanisms such as changes in the production or release of neurotrophic factors by the amacrine targets of the ION. Hence our hypothesis is that these effects are attributable to a novel mechanism: the initiation (or modulation) by electrical activity of retrograde signals to the ION from the level of the presynaptic axons.

However, before our hypothesis can be accepted, we first need to rule out the two main alternatives. Action potentials occur in the retina not only in isthmo-optic axons but in ganglion cells and in some amacrines. Despite the rapid occurrence of our effects in the ION, it still might be argued that they were attributable to retrograde signals initiated in the amacrine target cells, or they might be attributed to an anterograde pathway, of which the most plausible would be from retina to optic tectum to ION. The experiments described below rule out these alternatives and support our hypothesis.

\section{MATERIALS AND METHODS}

Fertile chicken eggs of the White Leghorn breed were incubated at $38^{\circ} \mathrm{C}$ and $60 \%$ relative humidity. The shell was opened over the air sac and the embryo's head gently raised. Pharmacological agents were injected slowly (over 20-30 sec) into the right eye, or into both eyes, through a $10 \mu \mathrm{l}$ Hamilton microsyringe. Then the eggs were sealed with adhesive tape and returned to the incubator.

Saxitoxin and Joro spider toxin fragment 3 (JSTX-3) were obtained from Calbiochem (Lucerne, Switzerland), kainate and colchicine from Sigma (St. Louis, MO), and D-3-(2-carboxypiperazin-4-yl)propyl-1phosphonic acid (D-CPP) from Tocris Cookson (Bristol, UK).

Embryos were killed at exactly E14. Brains and eyes were fixed by immersion in Carnoy's fixative, dehydrated, cleared, and embedded in paraffin wax. Serial sections were cut at $12 \mu \mathrm{m}$, coronally for the brains and parallel to the equatorial plane for the eyes, and were mounted on slides and stained with cresyl violet. 


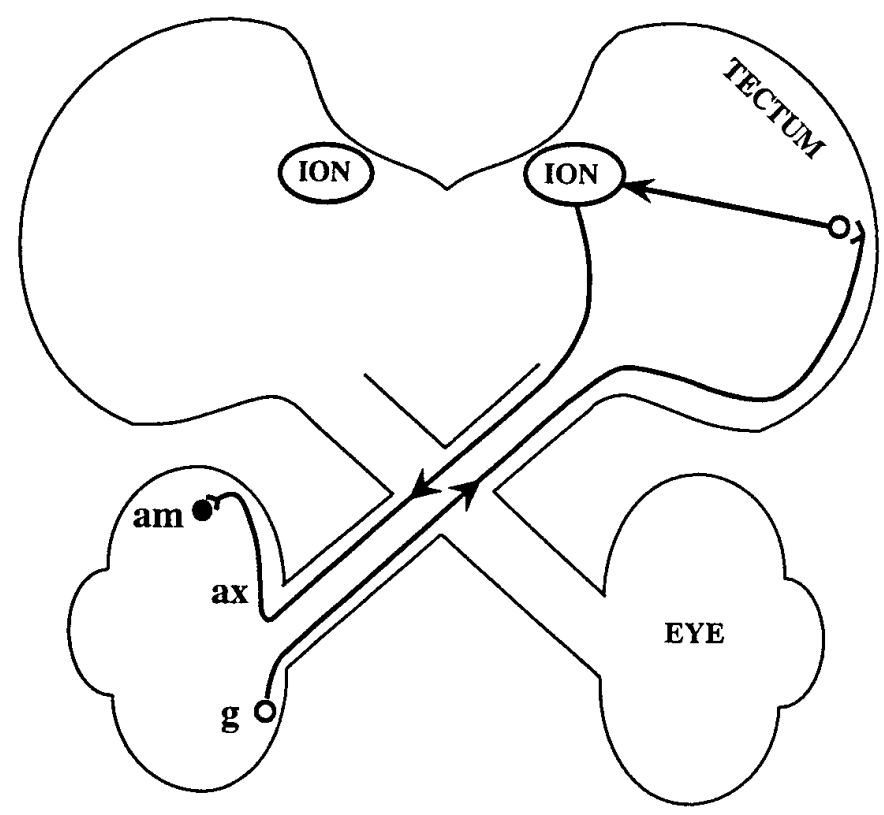

Figure 1. Diagram of the isthmo-optic nucleus and its main connections emphasizing the three intraretinal sites from which action potentials might initiate signals affecting the ION. Retrograde signals to the ION might arise from the intraretinal parts of the isthmo-optic axons, $a x$, or from the amacrine target cells, am. Anterograde signals might travel from ganglion cells, $g$, to the ION via one or more synapses in the optic tectum or conceivably by some other, as yet unknown, anterograde pathway.

We counted pyknotic cells in the three sections closest to the middle of the ION, and we took the mean as an indication of neuronal death in the ION. We chose to use pyknotic counts rather than to count all the ION neurons because we wanted to see the very earliest changes in cell death. Because pyknotic counts are a measure, albeit crude, of the rate of cell death, they are a sensitive measure of its onset or of changes in it; time derivatives are sharper than their integrals.

ION lamination was evaluated subjectively. To summarize our evaluations in graphic form, we calculated a lamination score by assigning points to each ION according to whether the lamination was normal (2 points), reduced ( 1 point), or absent ( 0 points) and calculating the means for each age.

Counts and lamination evaluations were performed in both IONs, the one ipsilateral to the injection being a control, because the isthmo-optic projection is $>99.8 \%$ crossed in E14 embryos. To eliminate nonspecific effects, we subtracted the control counts and lamination indices from those of the side contralateral to the injection.

\section{RESULTS}

Because lamination appears in the ION immediately before E14, all embryos were fixed at exactly E14. To evaluate how effects on the ION of intraocular injections depended on survival time, we varied the moment of injection but not the time of fixation.

\section{Intraocular saxitoxin injections decrease neuronal death and lamination in the ION within $6 \mathrm{hr}$}

Action potentials were blocked in the retina by means of saxitoxin, a blocker of voltage-dependent sodium channels. Although previous experiments from this laboratory involved the use of tetrodotoxin (Péquignot and Clarke, 1992a,b), we have switched to using saxitoxin, the action of which is identical to that of tetrodotoxin, because saxitoxin is commercially available in tritiated form, which is useful for tracking its diffusion out of the injected eye. Experiments that will be described in detail elsewhere showed that such diffusion occurs rather rapidly, causing systemic effects on the ION ipsilateral to the injection, with heavy doses of saxi- toxin and long survival times. However, in the present experiments involving moderate doses and short survival times, there were no detectable ipsilateral effects. Furthermore, the possibility of directed diffusion of saxitoxin along the optic nerve and tract can be excluded for a variety of reasons summarized in Catsicas et al. (1992).

Using methods described previously (Péquignot and Clarke, 1992a), we performed electrophysiological experiments to check the efficacy of various intraocularly injected doses of saxitoxin (always in $3 \mu$ l of saline) in blocking intraretinal action potentials. The smallest dose that reliably produced long-lasting blockade was found to be $0.05 \mu \mathrm{g}$, and we have used this routinely.

By counting total neuron numbers in both IONs, we confirmed that this intraocular dose of saxitoxin substantially reduces neuronal death in the ION in accordance with the previous tetrodotoxin experiments (M.-P. Primi, unpublished data). However, our main purpose was to test how soon this reduction occurred, and for this purpose we counted pyknotic cells (probably neurons) rather than healthy neurons. We found reduced numbers of pyknotic cells as few as $6 \mathrm{hr}$ postinjection (Fig. $2 A$ ). A reduction was, in fact, detectable at 6,9 , or $12 \mathrm{hr}$ postinjection, but not at $3 \mathrm{hr}$.

The effects of saxitoxin on ION lamination occurred even earlier, there being found in three of five embryos a minor reduction in lamination, as compared with the control (ipsilateral) ION, as few as $3 \mathrm{hr}$ postinjection. At 6 or $9 \mathrm{hr}$ postinjection there was a greater effect (Figs. $2 B, 3$ ), but total prevention of lamination did not occur until $12 \mathrm{hr}$.

\section{Intraocular kainate injections affect the ION only after 12-24 hr}

The above effects seemed surprisingly rapid to be mediated via cells postsynaptic to the isthmo-optic terminals, so we sought direct evidence as to how quickly the ION would respond to the destruction of its amacrine target cells. Kainate $(20 \mathrm{nmol}$ in $3 \mu \mathrm{l}$ of saline) therefore was injected into the right eye at various intervals before E14. An injection of this dose of kainate is known to kill most of the amacrine cells (and some cells of other classes, including ganglion cells), leading to the death of almost all of the ION neurons within 2-3 d (Catsicas and Clarke, 1987a,b).

Because the early time course of amacrine cell death after such injections had not been studied (at least not in vivo), we fixed retinas at $0.5,1$, and $6 \mathrm{hr}$ after kainate. As early as $0.5 \mathrm{hr}$ after kainate, the amacrine sublayer already contained large numbers of pyknotic, presumably dying, cells (Fig. 4). They were even more numerous at $1 \mathrm{hr}$, and by $6 \mathrm{hr}$ almost all of the amacrines were dead.

The response of the ION to the kainate injections was slower than to the above-described injections of saxitoxin. The pyknotic cell counts were unchanged at $12 \mathrm{hr}$ after kainate and only slightly increased at $18 \mathrm{hr}$ but were increased greatly at $24 \mathrm{hr}$ (Fig. $5 \mathrm{~A}$ ).

Lamination was reduced by the kainate injections, but again the effects were slower than after saxitoxin. Although there did seem to be a slight reduction in lamination at 12 and $18 \mathrm{hr}$ after kainate, it was not eliminated until $24 \mathrm{hr}$ after kainate (Figs. 5B, 6).

\section{Intraocular saxitoxin affects the ION even when its target cells have been destroyed}

To test more directly the possible role of the retinal target cells in the response of the ION to intraocular saxitoxin, we first injected kainate (20 nmol in $3 \mu \mathrm{l}$ of saline) into both eyes and then saxitoxin into the right eye 1 or $6 \mathrm{hr}$ later, when most of the amacrines were dead. We allowed 23 or $18 \mathrm{hr}$ survival time after 

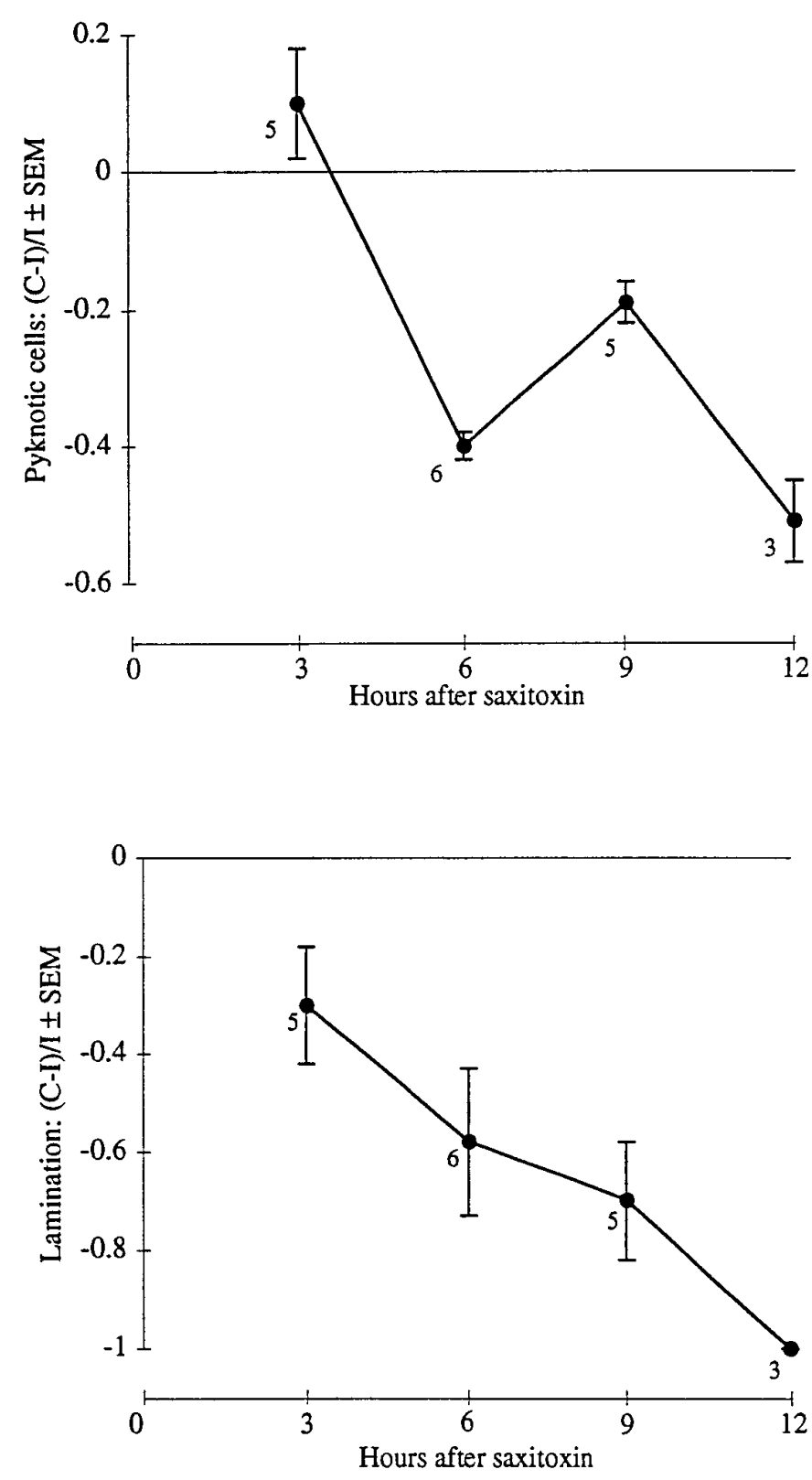

Figure 2. Effects on the ION of an intraocular injection of saxitoxin 3-12 hr before fixation at E14. Top, Proportional change below ipsilateral control of pyknotic cell count per section: count in the contralateral ION (C) minus the count for the ipsilateral ION $(I)$ divided by $I, \pm$ SEM. Bottom, Changes in lamination. This was judged subjectively as normal (2 points), reduced (1 point), or absent (0 points), and the mean at each time point was taken as lamination score. The ordinate shows proportional reduction below ipsilateral control $(I)$ of lamination score in ION contralateral to the injection $(C):(C-I) / I$. In both graphs, numbers near the points indicate sample size. For both pyknotic counts and lamination, mean $(C-I) / I$ is significantly below zero at $6 \mathrm{hr}(p=0.016$ for both, one-tailed Wilcoxon test) and at $9 \mathrm{hr}$ ( $p=0.031$ for both), but not at $3 \mathrm{hr}$. Significance was not tested at $12 \mathrm{hr}$ because $n=3$.

saxitoxin so that the total survival after kainate was $24 \mathrm{hr}$, when pyknosis in the ION was very high. The saxitoxin significantly reduced this induced pyknosis (Fig. 7). We could not, in this case, evaluate whether the saxitoxin reduced ION lamination, because it was eliminated in any event in both IONs as a result of the kainate injections.

\section{Reducing the activity of retinal cells does not rapidly affect the ION}

To confirm our hypothesis of presynaptically initiated retrograde signaling, we needed to rule out two alternative ways in which the rapid effects of saxitoxin on the ION might occur: by an indirect retrograde signal owing to activity blockade in the target cells of the ION (as discussed above) or by an anterograde signal owing to activity blockade in retinal ganglion cells leading changed firing in the afferents of the ION. The latter are mostly from the optic tectum (Crossland and Hughes, 1978). As a test of both alternatives, we reduced the activity of retinal neurons by injecting antagonists of excitatory amino acid receptors into the right eye at various intervals before E14. Each injection involved a cocktail containing the NMDA antagonist D-CPP and the irreversible non-NMDA antagonist JSTX-3 (Kawai et al., 1991). These antagonists were chosen partly because they are hydrophilic and diffuse only slowly out of the eye. We injected $2.7 \mu \mathrm{g}$ of D-CPP and $2.8 \mu \mathrm{g}$ of JSTX-3 (in $3 \mu$ l of saline), which we calculate to have produced concentrations of $\sim 100 \mu \mathrm{M}$ (D-CPP) and $50 \mu \mathrm{M}$ (JSTX-3) in the vitreous body. Injected separately into the eyes of E13 chick embryos, these doses have been shown to provide complete protection against excitotoxic death caused by intraocularly injected NMDA and AMPA, respectively, for at least $24 \mathrm{hr}$ (V. Castagné and M.-P. Primi, unpublished data).

To assay whether our cocktail actually was reducing the electrical activity of retinal ganglion cells, we made use of the fact that blocking such activity provokes neuronal death in the stratum griseum centrale (SGC) of the contralateral optic tectum (Catsicas et al., 1992). We counted the pyknotic SGC cells on both sides in E14 embryos that had received injections of the cocktail 12 (4 embryos) or $18 \mathrm{hr}$ ( 2 embryos) earlier. We counted all the pyknotic SGC cells in three sections on each side. In all six embryos there was an increase in the number of pyknotic cells in the SGC contralateral to (affected by) the injection: $34 \%$, on average, at 12 hr (mean of 127.8 contralaterally vs 95.3 ipsilaterally) and $60 \%$ at $18 \mathrm{hr}$ (mean of 132.7 contralaterally vs 82.9 ipsilaterally). In embryos of the same age, $12 \mathrm{hr}$ after an intraocular injection of saxitoxin there is an increase of $28 \%$ (A. Posada and M.-P. Primi, unpublished data). It would seem, therefore, that retinal ganglion cells of E13.5-E14 embryos have spontaneous activity and that our cocktail inhibited it more or less completely.

In the ION the effects of the cocktail were minimal. There were slight reductions in pyknotic cell numbers at 18 and $24 \mathrm{hr}$ postinjection but only by approximately three cells per section, a mere $20 \%$ of the control counts; at $12 \mathrm{hr}$ there was no effect at all (Fig. $5 A$ ). The degree of the ION lamination was indistinguishable between the two sides in all embryos, despite substantial variation between embryos (Fig. 5B).

\section{Inhibiting retinal protein synthesis does not (rapidly) affect neuronal death or lamination in the ION}

Because activity-induced changes in retrograde signals generally are attributed to changed postsynaptic production of trophic molecules, we tested the effects of inhibiting retinal protein synthesis by means of cycloheximide, which is known not to act on mitochondrial ribosomes and therefore will not have affected directly the isthmo-optic terminals (Tedeschi, 1976). At E13.5 we injected cycloheximide ( $20 \mu \mathrm{g}$ in $3 \mu \mathrm{l}$ of saline) into the right eye of five embryos. This heavy dose can be assumed to have inhibited retinal nonmitochondrial protein synthesis almost completely for the first few hours and by $>70 \%$ throughout the $12 \mathrm{hr}$ survival period (Blaser et al., 1991), but the dose proved somewhat toxic. 

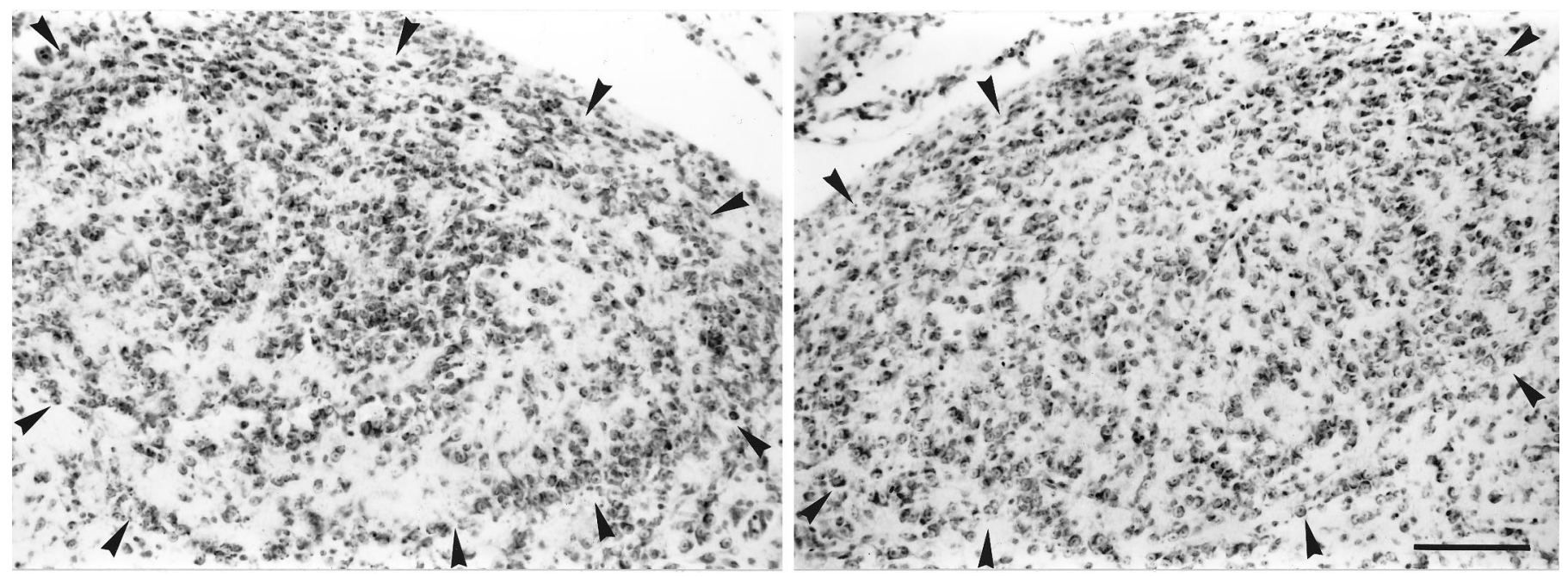

Figure 3. Appearance of the IONs ipsilateral (shown left) and contralateral (right) to an intraocular injection of saxitoxin $6 \mathrm{hr}$ before fixation at E14. The sections are coronal. Dorsal is up. Scale bar, $100 \mu \mathrm{m}$. The borders of the ION are indicated by arrows. In the contralateral ION the lamination is weaker (classified as "reduced") than in the ipsilateral one ("normal").

Figure 4. Effects of intraocularly injected kainate on the retina. The inner retina, with ganglion cell layer, is shown down. Right, Central retina $0.5 \mathrm{hr}$ after an intraocular injection of kainate. Note that there are already numerous pyknotic cells in the amacrine sublayer. Left, Control retina. Scale bar, $50 \mu \mathrm{m}$.
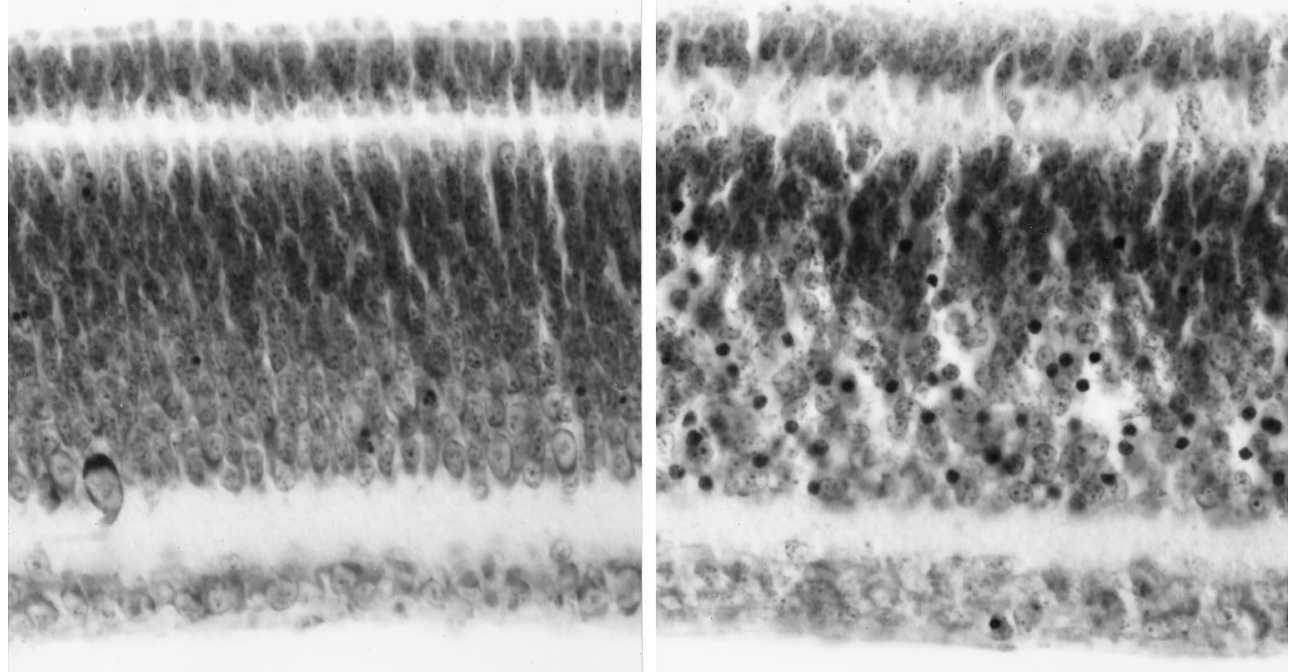

In the two embryos that survived to E14, we could detect no effect in the contralateral ION on pyknotic cell number (mean 12.5 per section contralaterally, 13.2 ipsilaterally) or on lamination (normal on both sides, Fig. 8).

\section{Colchicine experiments implicate axoplasmic transport in the retrograde signaling}

Our favored hypothesis implies the existence of one or more activity-dependent retrograde signals. The only known vehicle for such signals is retrograde axoplasmic transport, although we cannot rule out other theoretical possibilities such as antidromic action potentials (Pinault, 1995) or calcium waves (Ogawa et al., 1994). If axoplasmic transport is the vehicle, two predictions follow: (1) blocking axoplasmic transport in the eye by means of intraocularly injected colchicine should affect ION cell death and lamination after a delay similar to, or shorter than, that found with saxitoxin; and (2) intraocularly injected saxitoxin should have no effect in the presence of colchicine. We have tested these predictions.

To test the first prediction, we injected colchicine $(0.2 \mu \mathrm{g}$ in $3 \mu \mathrm{l}$ of saline) into the right eye. The results have been published elsewhere (Primi and Clarke, 1997), but we summarize them here because of their immediate relevance. Lamination was reduced at $9 \mathrm{hr}$ after colchicine but not at $6 \mathrm{hr}$. We were surprised to find a biphasic influence on ION pyknotic cell numbers. At $1.5 \mathrm{hr}$ after colchicine there was no effect, and then between 3 and $9 \mathrm{hr}$ there was a statistically significant reduction of $\sim 30 \%$ in the pyknotic counts, after which there was a return to no effect at $12 \mathrm{hr}$ and a massive increase in pyknotic counts at $18 \mathrm{hr}$. Discussion of the unexpected initial reduction in pyknotic counts is beyond the scope of this paper-see Primi and Clarke (1997). What is relevant in the present context is that the earliest effects occurred after intervals similar to or shorter than those after saxitoxin injection. In the case of pyknotic counts, an effect was detected earlier after colchicine $(3 \mathrm{hr})$ than after saxitoxin $(6 \mathrm{hr})$. In the case of lamination, an effect was found slightly earlier with saxitoxin (at $6 \mathrm{hr}$ or even apparently at $3 \mathrm{hr}$ in some embryos) than with colchicine $(9 \mathrm{hr})$. We consider this difference insufficient to refute our favored hypothesis (invoking activity-dependent signals 

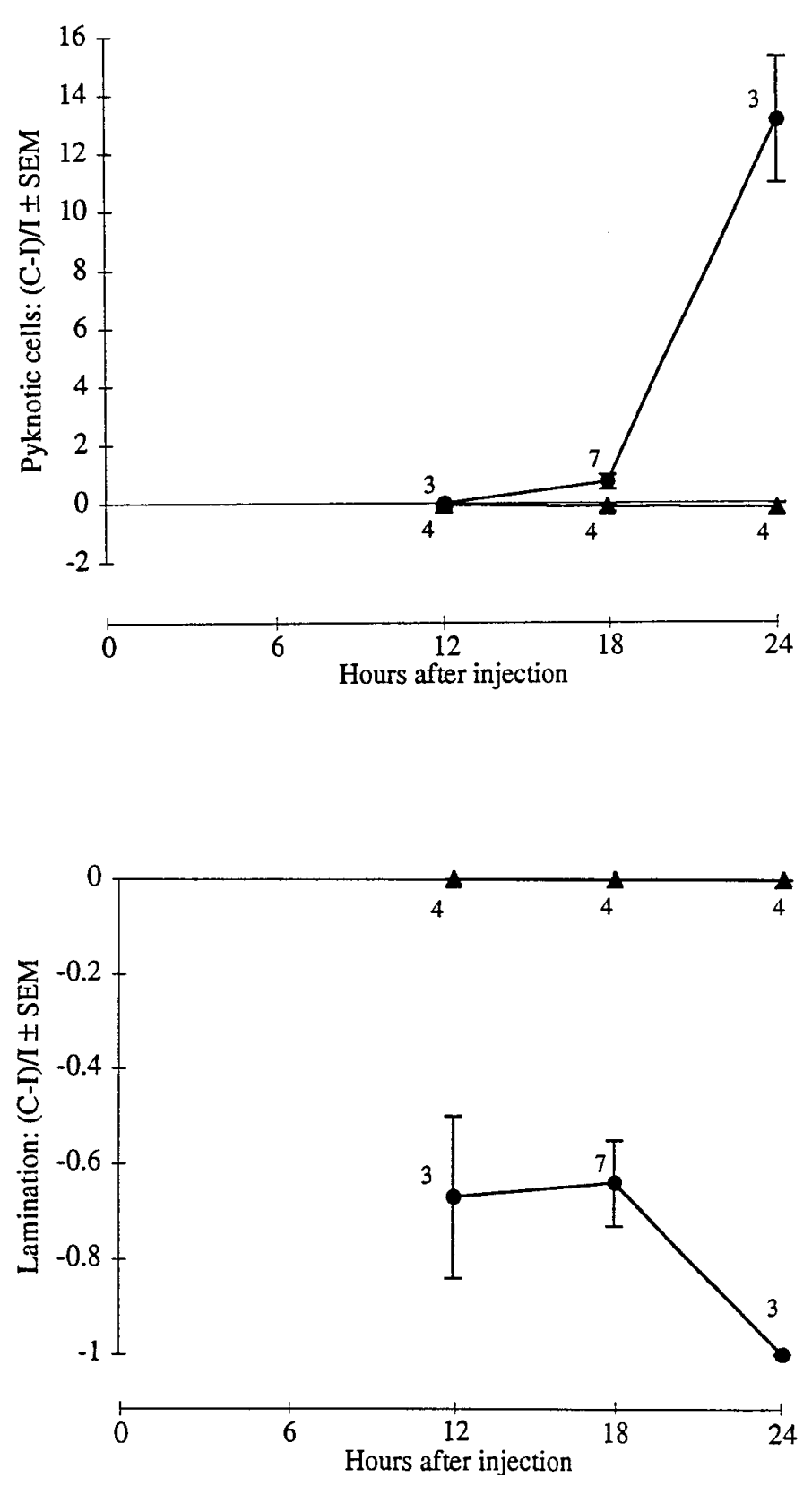

Figure 5. Effects on the ION of killing its target (and other retinal) cells with intraocularly injected kainate (circles) or reducing their activity with intraocularly injected blockers of excitatory amino acid receptors (triangles). For further details, see legend to Figure 2.

mediated by retrograde transport), because the $3 \mathrm{hr}$ effect with saxitoxin was not statistically significant and colchicine probably took an hour or more to block transport (see below). Moreover, colchicine may have affected lamination at times between 6 and 9 $\mathrm{hr}$ that were not tested.

To test the second prediction, we injected colchicine into both eyes to block axoplasmic transport and then injected saxitoxin into the right eye and checked to see whether there was any difference between the two IONs. Because colchicine takes time to cross the axonal membrane and because its reaction with tubulin is relatively slow (Wilson et al., 1974), whereas saxitoxin binds to receptors very quickly, it was necessary to inject the colchicine first and wait long enough for transport to be blocked before injecting the saxitoxin. Published in vitro experiments indicate that the time for colchicine to penetrate the axonal membrane and disrupt the movement of vesicles is $\sim 40 \mathrm{~min}$ (Brat and Brimijoin, 1992). To block transport as quickly as possible, we used in this second experiment a particularly strong dose $(1 \mu \mathrm{g}$ of colchicine per eye, $>100 \times$ threshold for transport blockade) and confirmed in tracing experiments that this blocked retrograde transport within $1 \mathrm{hr}$ (Primi, unpublished data). To make absolutely certain that transport would be blocked at the time of saxitoxin injection, we allowed $2 \mathrm{hr}$ after the bilateral colchicine injection before injecting saxitoxin into the right eye, after which a further $6 \mathrm{hr}$ was allowed before death at E14. In the ION the pyknotic counts were almost identical on the two sides, $11.9 \pm 3.3 \mathrm{SE}$ per section contralaterally and $11.6 \pm 5.4 \mathrm{SE}$ ipsilaterally. The degree of lamination did not differ reliably between the two sides: in only two of the seven embryos was there any difference, the contralateral ION being slightly less laminated in these.

\section{DISCUSSION}

The central observations in this paper are the very rapid effects of intraocular saxitoxin on ION pyknosis (by $6 \mathrm{hr}$ ) and on lamination (by 6 or even $3 \mathrm{hr}$ ). The occurrence of retrograde (as we shall argue) changes so soon after saxitoxin injection is remarkably rapid, given that retrograde transport from the eye to the ION takes almost $3 \mathrm{hr}$ in E13-E14 embryos (Clarke and Cowan, 1976), but it is compatible with the fastest effects reported in other systems after axotomy: increased pyknotic counts after $4 \mathrm{hr}$ for axotomized retinal ganglion cells in neonatal rats (Horsburgh and Sefton, 1987; Harvey and Robertson, 1992) or after 8-10 hr for axotomized motor and sensory neurons in chick embryos (Oppenheim et al., 1990). The timing of retrograde effects after target activity blockade has not been investigated previously.

\section{The presynaptic initiation hypothesis and its alternatives}

The main conclusion of this paper is that the arrival of action potentials in the distal (retinal) parts of isthmo-optic axons initiates (or modulates) one or more retrograde signals to the parent cell, thereby affecting the number of pyknotic cells and the degree of lamination in the ION. For this novel hypothesis to be accepted, we have to rule out the two more conventional alternatives discussed below.

\section{The anterograde route hypothesis}

It might be suggested that the rapid effects of intraocular saxitoxin on the ION were mediated anterogradely, the most probable route being via the optic tectum (see Fig. 1). This interpretation might seem attractive because the anterograde signals could be carried by action potentials, thereby explaining the rapidity of the effects. However, as summarized in Table 1, four lines of evidence indicate that neither the effect on ION pyknotic count nor that on lamination can be explained by the anterograde route.

First, we deliberately fixed the embryos at E14, when the ION is only beginning to receive its first synapses (Angaut and Raffin, 1981) and is insensitive to ablation of the ipsilateral optic tectum, its main source of afferents. In embryos fixed at E14, tectal lesions performed 2-3 d earlier have no effect on ION neuronal number (Clarke, 1985) nor pyknotic cell counts (Posada, unpublished data) nor lamination (Clarke and Kraftsik, 1996).

Second, the observed decrease in pyknotic counts is the opposite to what the anterograde route hypothesis would predict. If retinal activity blockade affects the activity in afferents to the ION at E13-E14, it would be expected to reduce it (Uchiyama, 1989), 

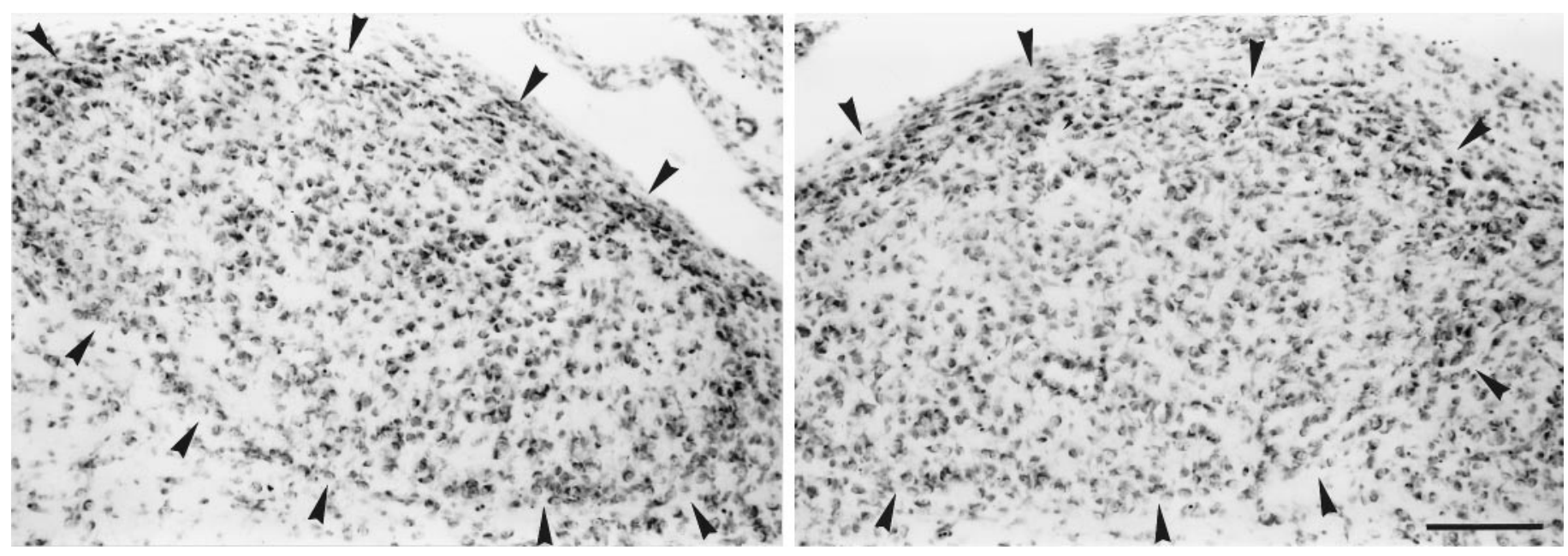

Figure 6. Appearance of the IONs ipsilateral (shown left) and contralateral (right) to an intraocular injection of kainate $12 \mathrm{hr}$ before fixation at E14. The sections are coronal. Dorsal is up. Scale bar, $100 \mu \mathrm{m}$. The borders of the ION are indicated by arrows. There is only a slight difference in lamination between the contralateral ION (classified as "reduced") and the ipsilateral one ("normal").

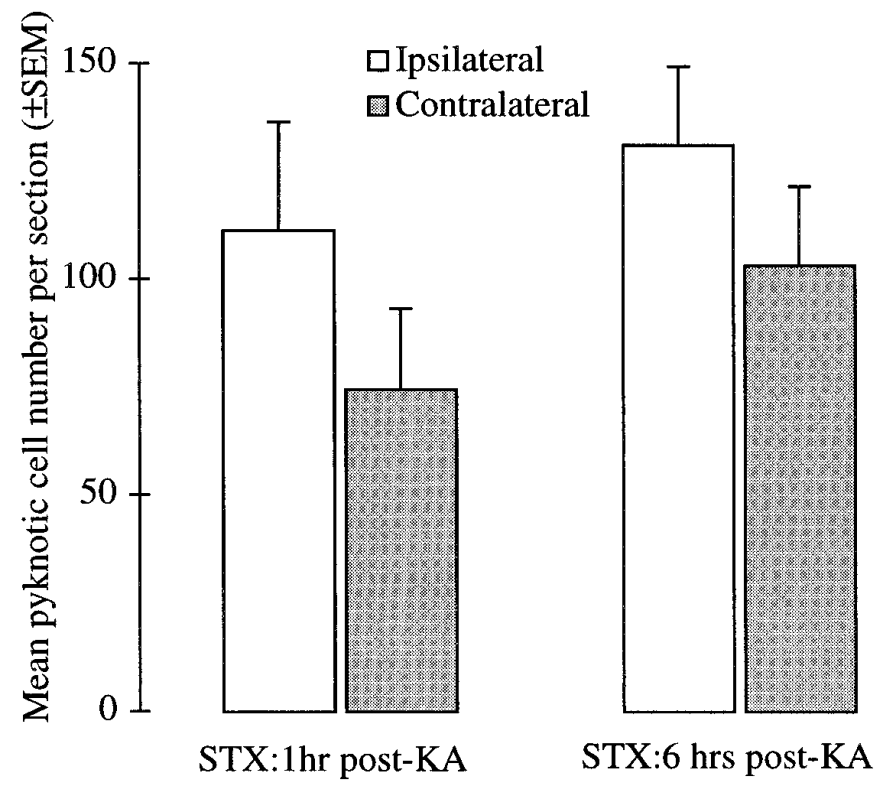

Figure 7. The effects on ION pyknotic counts of an intraocular saxitoxin $(S T X)$ injection after bilateral destruction of the target cells of the ION by kainate. Saxitoxin was injected into the right eye $1 \mathrm{hr}(l e f t, n=4)$ or $6 \mathrm{hr}$ (right, $n=5$ ) after the injection of kainate into both eyes at E13.0, and the embryos were fixed at E14.0. The reduction caused by saxitoxin is significant in both histograms: $p=0.026$ (left); $p=0.024$ (right) (one-tailed $t$ test).

but all studies on the effects of blocking afferent activity report an increase in cell death and pyknosis, not a decrease (Wright, 1981; Born and Rubel, 1988; Catsicas et al., 1992; Galli-Resta et al., 1993).

Third, intraocularly injected glutamate receptor antagonists, shown by their effect on the tectal SGC to have greatly reduced ganglion cell activity, did not affect ION pyknotic counts or lamination.

Fourth, because the vehicle over this polysynaptic route presumably would be electrical activity, one would not expect the effects of saxitoxin to be blocked by intraocular colchicine. Yet the
Table 1. Tests of the anterograde route hypothesis

Result/Reject hypothesis?

\begin{tabular}{lll}
\cline { 2 - 3 } Experiment & Pyknotic counts & Lamination \\
\hline $\begin{array}{l}\text { Previous experiments } \\
\text { Tectal lesions }\end{array}$ & No effect/Reject & No effect/Reject \\
$\begin{array}{c}\text { Sign of effect after } \\
\text { afferent blockade }\end{array}$ & Increase/Reject & Not tested \\
$\begin{array}{c}\text { Present experiments } \\
\text { Intraocular glutamate } \\
\text { antagonists }\end{array}$ & No effect/Reject & No effect/Reject \\
$\begin{array}{c}\text { Intraocular colchicine } \\
\text { and then saxitoxin }\end{array}$ & No effect/Reject & No effect?/Reject?
\end{tabular}

${ }^{a}$ After tectal lesions at E11-E12, there was found at E14 no difference in total ION neuron numbers (Clarke, 1985) or in pyknotic counts (A. Posada, unpublished data) and no change in lamination (Clarke and Kraftsik, 1996).

${ }^{b}$ All previous reports show increased cell death (see text).

effect of saxitoxin on ION pyknotic cell numbers was abolished totally by colchicine; the effect on lamination appears to have been blocked likewise, although in two of eight embryos the lamination was noticeably weaker in the ION projecting to the saxitoxin-injected eye.

Taken together, these four arguments refute the anterograde route hypothesis.

\section{The postsynaptically mediated retrograde signal hypothesis}

In the light of current theory, intraocular saxitoxin might be supposed to affect the ION by modifying the production and/or release of trophic factors in the retinal target cells (Thoenen, 1995), but we have six arguments that such a mechanism cannot explain the present effects (Table 2).

First, saxitoxin would be expected to decrease, not increase, trophic factor synthesis (Zafra et al., 1991; Lindholm et al., 1994), and sodium inflow is necessary for activity-dependent release (Blöchl and Thoenen, 1996). The observed decrease in ION neuronal death is, therefore, the opposite of what would be predicted.

Second, the effects on ION pyknotic counts of intraocular 

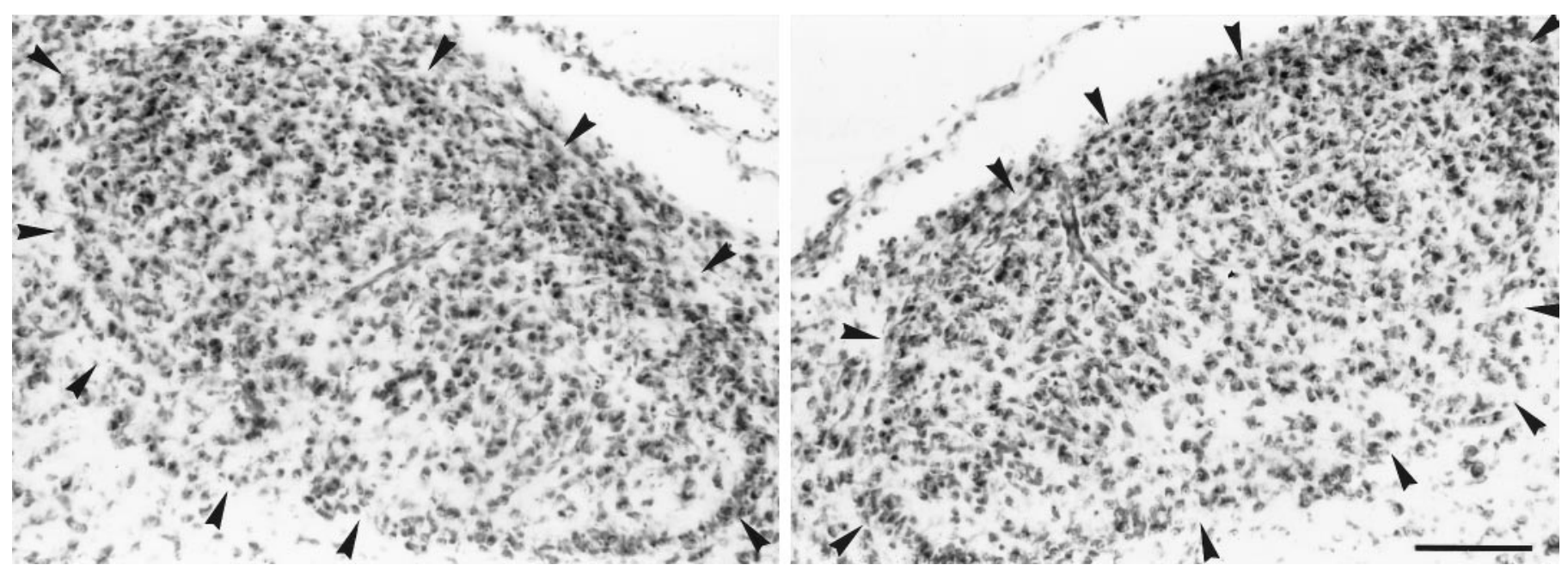

Figure 8. Appearance of the IONs ipsilateral (shown left) and contralateral (right) to an intraocular injection of cycloheximide $12 \mathrm{hr}$ before fixation at E14. The sections are coronal. Dorsal is up. Scale bar, $100 \mu \mathrm{m}$. The borders of the ION are indicated by arrows. The lamination was classified as normal in each ION.

Table 2. Tests of the postsynaptically mediated retrograde signal hypothesis

Result/Reject hypothesis?

Experiment

Pyknotic counts

Lamination

Previous experiment

Effect of electrical activity on synthesis/release of trophic factor

Present experiments

Timing after intraocular $\mathrm{BDNF}^{a}$ vs saxitoxin

Timing after intraocular kainate vs saxitoxin

Saxitoxin after intraocular kainate

Intraocular glutamate antagonists

Cycloheximide $^{b}$

Increase/ Reject

BDNF slower/Reject

Kainate slower/Reject

Pyknosis reduced/Reject

No effect/Reject

No effect/Reject
Inconclusive

Inconclusive

Kainate slower/Reject

Inconclusive

No effect/Reject

No effect/Reject

${ }^{a}$ Intraocularly injected brain-derived neurotrophic factor (BDNF) took 18-24 hr to reduce ION pyknotic counts (Primi and Clarke, 1996).

${ }^{b}$ Evaluates only role of transcription/translation in retina; does not exclude post-translational postsynaptic mechanisms.

saxitoxin occurred much earlier (6 hr) than those recently reported (Primi and Clarke, 1996) of intraocular brain-derived neurotrophic factor $(18-24 \mathrm{hr})$.

Third, for both pyknotic counts and lamination the changes occurred in the ION much later after kainate $(\sim 18 \mathrm{hr})$ than after saxitoxin $(\sim 6 \mathrm{hr})$. Less than one-half of the difference may be explained by some amacrine cells surviving several hours after the injection. The isthmo-optic target cells, which are a small minority of the amacrines (Uchiyama et al., 1995), appear to be killed by intraocular kainate just as the other amacrines are, because the ION subsequently degenerates (Catsicas and Clarke, 1987b). Moreover, many of the target cells are believed to be "proprioretinal cells" projecting from ventral to dorsal retina (Catsicas et al., 1987), and retrogradely labeled proprioretinal cells all disappear rapidly after a kainate injection into the eye (M. Catsicas, unpublished data). The present slow retrograde reaction to kainate contrasts with the very rapid reaction $(4 \mathrm{hr})$ in neonatal rats of retinal ganglion cells to intracollicular kainate injection (Horsburgh and Sefton, 1987). Because of this discrepancy and because in our experiments spilled contents of the kainate-killed retinal cells might have provided temporary trophic support to the isthmo-optic axons, our case cannot be based solely on the slow reaction of the ION to intraocular kainate.
Our fourth argument is that a reduction in ION pyknotic count after intraocular saxitoxin was still obtained even when the target cells first had been destroyed by kainate. This argument does not apply to the effect on lamination, because kainate alone prevented it, so that a subsequent influence of saxitoxin could not be tested.

Fifth, intraocular cycloheximide did not affect ION pyknotic count or lamination-a fact previously reported in older chick embryos (Blaser et al., 1991). This implies that changes in transcription or translation are unlikely to be responsible for the early effects of saxitoxin but leaves open a possible role for posttranslational events.

Our sixth argument stems from the fact that intraocular injection of glutamate receptor antagonists did not affect pyknotic cell numbers or lamination in the ION. Because these antagonists reduced the activity of retinal cells, this result indicates that postsynaptic activity was not the origin of the retrograde signals. Virtually all amacrines in E13 chick embryos carry glutamate receptors (Zeevalk et al., 1989), and the target cells are unlikely to be an exception given that they are killed by kainate, as is discussed above.

Taken together, these six arguments constitute a strong case for rejecting the postsynaptically mediated retrograde signal hypothesis. 


\section{Mechanisms for presynaptically initiated retrograde signaling}

Because, in the presence of intraocular colchicine, we found no effect of intraocular saxitoxin on ION pyknotic counts and only a marginal effect on ION lamination, the fast retrograde signals by which retinal activity affects neuronal survival and lamination in the ION presumably were carried mainly by axonal transport. That this may not be the sole carrier of the signal(s) affecting lamination is hinted at by the slight effects on lamination in a few animals of saxitoxin at only $3 \mathrm{hr}$ when given alone and at $6 \mathrm{hr}$ in the presence of colchicine. If these latter effects can be confirmed, it will be necessary to consider alternative signaling mechanismse.g., by antidromic action potentials (Pinault, 1995) or calcium waves (Ogawa et al., 1994)—but for the moment we limit discussion to signaling via retrograde transport.

Conventionally, retrograde signaling is attributed to receptormediated endocytosis of neurotrophic factors at the axon terminal, followed by retrograde transport of the receptor-ligand complex, which is viewed as signal carrier (DiStefano et al., 1992; Laduron, 1995). However, other molecules with signaling capacity, such as G-protein subunits and various kinases, are transported retrogradely, and these also may be involved (Hendry et al., 1995; Johanson et al., 1995; Ambron and Walters, 1996). The retrograde effects of presynaptic electrical activity may be attributable to the modulation of either kind of signal or they may be attributable to the initiation of new signal(s), in which case the second mechanism is more likely to be involved. Our experiments in progress indicate that the first step after the arrival of an action potential is the entry of calcium through N-type voltagedependent channels (Posada et al., 1996), and we are attracted by the possibility that this may initiate a rapid death signal (Primi and Clarke, 1997), although it alternatively may diminish an ongoing life signal.

\section{Implications of the presynaptic initiation hypothesis}

What could be the purpose of such a presynaptic mechanism? One possibility is that computations may take place in the terminal via interaction between intercellular signals from bound neurotrophic factors and internal signals caused by the action potential. The resultant nonredundant signal then would be transmitted to the cell body. It might, for example, reflect the success of presynaptic action potentials in modulating activity-dependent release of trophic molecules. It is possible to devise schemes according to which such a signal could reflect a "Hebbian" change in synaptic strength and instruct the cell body how to modify its synthetic machinery accordingly.

\section{REFERENCES}

Ambron RT, Walters ET (1996) Priming events and retrograde injury signals-a new perspective on the cellular and molecular biology of nerve regeneration. Mol Neurobiol 13:61-79.

Angaut P, Raffin JP (1981) Embryonic development of the nucleus isthmo-opticus in the chick: a Golgi and electron microscopic study. Dev Neurosci 4:1-14.

Bear MF, Colman H (1990) Binocular competition in the control of geniculate cell size depends upon visual cortical $N$-methyl-D-aspartate receptor activation. Proc Natl Acad Sci USA 87:9246-9249.

Blaser PF, Catsicas S, Clarke PGH (1991) Limits to the dependence of developing neurons on protein synthesis in their axonal target territory. Anat Embryol (Berl) 184:15-24.

Blöchl A, Thoenen H (1996) Localization of cellular storage compartments and sites of constitutive and activity-dependent release of nerve growth factor (NGF) in primary cultures of hippocampal neurons. Mol Cell Neurosci 7:173-190.
Born DE, Rubel EW (1988) Afferent influences on brainstem auditory nuclei of the chicken: presynaptic action potentials regulate protein synthesis in nucleus magnocellularis neurons. J Neurosci 8:901-919.

Brat DJ, Brimijoin S (1992) A paradigm for examining toxicant effects on viability, structure, and axonal transport of neurons in culture. Mol Neurobiol 6:125-135.

Catsicas M, Péquignot Y, Clarke PGH (1992) Rapid onset of neuronal death induced by blockade of either axoplasmic transport or action potentials in afferent fibers during brain development. J Neurosci 12:4642-4650.

Catsicas S, Clarke PGH (1987a) Spatiotemporal gradients of kainate sensitivity in the developing chicken retina. J Comp Neurol 262:512-522.

Catsicas S, Clarke PGH (1987b) Abrupt loss of dependence of retinopetal neurons on their target cells, as shown by intraocular injections of kainate in chick embryos. J Comp Neurol 262:523-534.

Catsicas S, Catsicas M, Clarke PGH (1987) Long-distance intraretinal connections in birds. Nature 326:186-187.

Clarke PGH (1985) Neuronal death during development in the isthmooptic nucleus of the chick: sustaining role of afferents from the tectum. J Comp Neurol 234:365-379.

Clarke PGH (1991) The roles of trophic communication in biological neural networks. Concepts Neurosci 2:201-219.

Clarke PGH (1992) Neuron death in the developing avian isthmo-optic nucleus, and its relation to the establishment of functional circuitry. J Neurobiol 23:1140-1158.

Clarke PGH, Cowan WM (1976) The development of the isthmo-optic tract in the chick, with special reference to the occurrence and correction of developmental errors in the location and connections of isthmooptic neurons. J Comp Neurol 167:143-164.

Clarke PGH, Kraftsik R (1996) Dendritic reorientation and cytolamination during the development of the isthmo-optic nucleus in chick embryos. J Comp Neurol 365:96-112.

Cowan WM, Wenger E (1968) The development of the nucleus of origin of centrifugal fibers to the retina in the chick. J Comp Neurol 133:207-240.

Crossland WJ (1979) Retinal afferents affect the formation of the avian ectomamillary nucleus. Brain Res 165:127-132.

Crossland WJ, Hughes CP (1978) Observations on the afferent and efferent connections of the avian isthmo-optic nucleus. Brain Res 145:239-256.

DiStefano PS, Friedman B, Radziejewski C, Alexander C, Boland PS, Lindsay RM, Wiegand SJ (1992) The neurotrophins BDNF, NT-3, and NGF display distinct patterns of retrograde axonal transport in peripheral and central neurons. Neuron 8:983-993.

Fritzsch B, Crapon de Caprona MD, Clarke PGH (1990) Development of two morphological types of retinopetal fibers in chick embryos, as shown by the diffusion along axons of a carbocyanine dye in the fixed retina. J Comp Neurol 300:405-421.

Galli-Resta L, Ensini M, Fusco E, Gravina A, Margheritti B (1993) Afferent spontaneous electrical activity promotes the survival of target cells in the developing retinotectal system of the rat. J Neurosci 13:243-250.

Harvey AR, Robertson D (1992) Time-course and extent of retinal ganglion cell death following ablation of the superior colliculus in neonatal rats. J Comp Neurol 325:83-94.

Hendry IA, Johanson SO, Heydon K (1995) Retrograde axonal transport of the $\alpha$ subunit of the GTP-binding protein $\mathrm{G}_{\mathrm{z}}$ to the nucleus of sensory neurons. Brain Res 700:157-163.

Horsburgh GM, Sefton AJ (1987) Cellular degeneration and synaptogenesis in the developing retina of the rat. J Comp Neurol 263:553-566.

Johanson SO, Crouch MF, Hendry IA (1995) Retrograde axonal transport of signal transduction proteins in rat sciatic nerve. Brain Res 690:55-63.

Kawai N, Miwa A, Shimazaki K, Sahara Y, Robinson HP, Nakajima T (1991) Spider toxin and the glutamate receptors. Comp Biochem Physiol [C] 98:87-95.

Laduron PM (1995) Functional consequences of retrograde axonal transport of receptor-bound neurotensin. Trends Pharmacol Sci 16:338-343.

Lindholm D, Castrén E, Berzaghi M, Blöchl A, Thoenen H (1994) Activity-dependent and hormonal regulation of neurotrophin mRNA levels in the brain-implications for neuronal plasticity. J Neurobiol 25:1362-1372.

Ogawa H, Oka K, Fujita S (1994) Calcium wave propagation in the giant axon of the earthworm. Neurosci Lett 179:45-49. 
O'Leary DDM, Cowan WM (1984) Survival of isthmo-optic neurons after early removal of one eye. Brain Res 314:293-310.

Oppenheim RW, Prevette D, Tytell M, Homma S (1990) Naturally occurring and induced neuronal death in the chick embryo in vivo requires protein and RNA synthesis: evidence for the role of cell death genes. Dev Biol 138:104-113.

Péquignot Y, Clarke PGH (1992a) Changes in lamination and neuronal survival in the isthmo-optic nucleus following the intraocular injection of tetrodotoxin in chick embryos. J Comp Neurol 321:336-350.

Péquignot Y, Clarke PGH (1992b) Maintenance of targeting errors by isthmo-optic axons following the intraocular injection of tetrodotoxin in chick embryos. J Comp Neurol 321:351-356.

Pinault D (1995) Backpropagation of action potentials generated at ectopic axonal loci-hypothesis that axon terminals integrate local environmental signals [Review]. Brain Res Rev 21:42-92.

Posada A, Primi M-P, Clarke PGH (1996) Action potentials initiate retrograde trophic signals from a presynaptic locus: the role of calcium. Eur J Neurosci [Suppl 9]:38.

Primi M-P, Clarke PGH (1996) Retrograde neurotrophin-mediated control of neurone survival in the developing central nervous system. NeuroReport 7:473-476.

Primi M-P, Clarke PGH (1997) Early retrograde effects of blocking axoplasmic transport in the axons of developing neurons. Dev Brain Res, in press.

Tedeschi H (1976) Mitochondria: structure, biogenesis, and transducing functions. NY: Springer.
Thoenen H (1995) Neurotrophins and neuronal plasticity. Science 270:593-598.

Uchiyama H (1989) Centrifugal pathways to the retina: influence of the optic tectum. Vis Neurosci 3:183-206.

Uchiyama H, Ito H, Tauchi M (1995) Retinal neurones specific for centrifugal modulation of vision. NeuroReport 6:889-892.

von Bartheld CS, Kinoshita Y, Prevette D, Yin Q-W, Oppenheim RW, Bothwell M (1994) Positive and negative effects of neurotrophins on the isthmo-optic nucleus in chick embryos. Neuron 12:639-654.

Wilson L, Bamburg JR, Mizel SB, Grisham LM, Creswell KM (1974) Interaction of drugs with microtubule proteins. Fed Proc 33:158-166.

Wingate RJT, Thompson ID (1994) Targeting and activity-related dendritic modification in mammalian retinal ganglion cells. J Neurosci 14:6621-6637.

Wright L (1981) Cell survival in chick embryo ciliary ganglion is reduced by chronic ganglionic blockade. Brain Res 227:283-286.

Zafra F, Castren E, Thoenen H, Lindholm D (1991) Interplay between glutamate and gamma-aminobutyric acid transmitter systems in the physiological regulation of brain-derived neurotrophic factor and nerve growth factor synthesis in hippocampal neurons. Proc Natl Acad Sci USA 88:10037-10041.

Zeevalk GD, Hyndman AG, Nicklas WJ (1989) Excitatory amino acidinduced toxicity in chick retina: amino acid release, histology, and effects of chloride channel blockers. J Neurochem 53:1610-1619. 